\title{
Remesas desde la perspectiva de los organismos internacionales: construcción de un desafío y elaboración de una agenda política internacional
}

\author{
ANTOINE PÉCOUD*
}

RESUMEN: El interés de los organismos internacionales por las relaciones existentes entre migración y desarrollo ha crecido durante los últimos 15 años. Tanto por su volumen como por sus repercusiones en las regiones de origen de los migrantes, las remesas son una ilustración particularmente clara de cómo estas últimas pueden contribuir al desarrollo. Para ciertos organismos internacionales estos envíos de dinero constituyen un elemento fundamental para la definición de las distintas realidades migratorias y para la elaboración de las recomendaciones dirigidas a los Estados. En particular, el Banco Mundial ha desempeñado un papel importante en la revalorización de las remesas y en la recolección de datos empíricos acerca del tema. En el presente artículo se analizan los discursos de los organismos internacionales sobre las remesas y se muestra que a pesar de su tono tecnocrático y apolítico, éstas desarrollan una visión del mundo que pertenece a un contexto ideológico y político y que además comporta una serie de prescripciones relativas al comportamiento que deberían adoptar tanto los Estados, como el sector privado y los propios migrantes. PALABRAS CLAVE: remesas, migración, desarrollo, organismos internacionales, discurso internacional sobre la migración.

\footnotetext{
* Profesor de Sociología de la Universidad París 13, Francia.
} 
ABSTRACT: The interest of international organizations in the relationships that exist between migration and development has grown during the past fifteen years. For both their volume as well as the repercussions in migrant regions of origin, remittances are a particularly vivid illustration of how development may be pursued. Thus, for some international organizations, the sending of money is a key element in the understanding of distinct migrant realities and for the creation of policy recommendations for the United States. The World Bank has played a particularly important role in the re-evaluation of remittances and in the collection of empirical data on the topic. In this article, we analyze the debates among international organizations regarding remittances and show that - despite their technocratic and apolitical tone- a vision of the world is presented that belongs to a particular ideological and political context and, further, that prescribes a series of prescriptions that should be adopted by the States involved, the private sector, and migrants themselves.

KEY WORDS: remittances, migration, development, international organizations, international discourse on migration. 


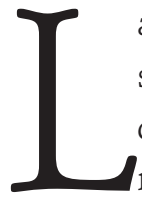

as sumas de dinero que los migrantes envían a sus países de origen se han convertido, en unos pocos años, en el objeto de profundos debates a nivel internacional. El volumen de las remesas - 436,000 millones de dólares en 2014, según el Banco Mundial (2015) - ha llamado la atención de los actores del desarrollo, comenzando por los organismos internacionales (OI) que las han adoptado como un argumento central de sus preconizaciones en materia de política de migración y desarrollo. Más adelante se analizará la manera en que los (OI) perciben las remesas ${ }^{1}$ y definen una agenda política basada en sus supuestas consecuencias en el desarrollo.

El presente artículo comienza con la descripción del lento surgimiento de los desafíos migratorios como un objetivo internacional y de la manera en que se fue constituyendo un discurso internacional sobre la migración a lo largo de los últimos 20 años. Enseguida se presenta el contenido de dicho discurso y el papel que en él ocupan las remesas, así como las relaciones entre este discurso y la investigación científica dedicada a esta misma cuestión. Más adelante, se pone en claro la opinión de los organismos internacionales respecto a la manera en que los gobiernos, los bancos y los migrantes deberían interactuar. Luego se muestra que esta representación de las remesas y de su utilidad para el desarrollo no es neutral y se inscribe en un contexto político e ideológico específico que valoriza ciertos aspectos de la realidad al mismo tiempo que desatiende otros. A manera de conclusión se presentan

${ }^{1}$ Generalmente, se entiende por remesas las sumas de dinero que los trabajadores migrantes internacionales envían a sus países de origen, la mayoría de las veces a miembros de su familia o allegados. Sin embargo, esta definición somera es objeto de debate. El Fondo Monetario Internacional (FMI), por ejemplo, ha desarrollado una definición mucho más precisa de las remesas, utilizada para elaborar estadísticas a este respecto (FMI, 2009). Por otro lado, y bajo una perspectiva más sociológica, Carling (2008: 46-48) señala la heterogeneidad de las remesas: no todas corresponden a esa forma estereotipada mencionada anteriormente (el dinero no es siempre enviado al país de origen de los migrantes, tampoco es siempre enviado por los migrantes mismos, etcétera). Finalmente, Levitt propone el concepto de «remesas sociales» (social remittances) para designar los flujos no monetarios (ideas, valores, normas, prácticas, competencias, aspiraciones, etcétera) que circulan entre los migrantes y sus sociedades de origen, y pueden tener consecuencias sobre el desarrollo (Levitt y LambaNieves, 2011). 
algunas de las ideas sobre las que se reflexiona actualmente en el Banco Mundial, según las cuales las remesas deberían ser incluidas en las estrategias financieras para el desarrollo.

\section{INTERNACIONALIZACIÓN DE LOS DESAFÍOS MIGRATORIOS}

A pesar de ser un reto transnacional por definición, las migraciones internacionales estuvieron por largo tiempo ausentes de la agenda de los organismos internacionales y de los debates de lo que llamamos «la comunidad internacional».

En 1919, año de su creación, la Organización Internacional del Trabajo (OIT) fue el primer organismo internacional que abordó la problemática migratoria desde el ángulo de la protección de los derechos de los trabajadores migrantes. El periodo comprendido entre 1870 y 1914, a menudo calificado como "la primera globalización», se había caracterizado por importantes movimientos de migración laboral. Ante los ojos de los sindicatos en particular (miembros de la ort, al mismo título que los gobiernos y los empleadores), estas migraciones representaban una amenaza para las condiciones de trabajo, ya que permitían a los empleadores poner en competencia a los trabajadores migrantes y no migrantes. En consecuencia, resultaba necesario mejorar la protección de los migrantes para evitar diferencias de trato demasiado grandes. Sin embargo, los esfuerzos de la ort fueron atajados por el contexto de la época, marcado por la crisis económica de los años treinta y por la exacerbación de los nacionalismos (Rosental, 2006). Más tarde, después de la Segunda Guerra Mundial, en una época de crecimiento económico y de una necesidad renovada de mano de obra extranjera, la ort emprendió nuevas negociaciones cuyo fruto fueron dos convenios adoptados: el Convenio 97 sobre los trabajadores migrantes (revisado) en 1949 y el Convenio 143 sobre los trabajadores migrantes (disposiciones complementarias) en 1975.

$36 \frac{\text { SEGUNDO SEMESTRE } 2015}{\text { MIGRACIÓN Y DESARROLLO NÚM. } 25}$ 
En 1990, la Organización de las Naciones Unidas (ONU) tomó el relevo al adoptar la Convención Internacional sobre la Protección de los Derechos de todos los Trabajadores Migratorios y de sus Familiares, el instrumento jurídico internacional más ambicioso en la materia, que depende de la Oficina del Alto Comisionado para los Derechos Humanos (ACNUDH) y no de la OIT. No obstante, muchas naciones se han mostrado reticentes ante los tratados de la onu y de la ort por igual. La Convención de la onu sólo ha sido ratificada por 50 países, y entre ellos no se encuentra ningún país occidental receptor de migrantes. Por el contrario, los países de origen de los migrantes se muestran más favorables a estas iniciativas internacionales, pues esperan que con ellas se refuerce la protección de sus ciudadanos emigrantes. Así, a pesar de casi un siglo de esfuerzos, los or no han logrado que los derechos de los trabajadores migrantes se conviertan en una verdadera empresa de la cooperación internacional (De Guchteneir y Pécoud, 2010). Este fracaso contrasta con el «éxito» de la cuestión de los refugiados que, con la creación del Alto Comisionado de Naciones Unidas para los Refugiados (ACNUR) en 1950 y la adopción de la Convención de Ginebra en 1951, se convirtió en un ámbito de acción legítimo de la ONU. Esta distinción entre «refugiados»y «migrantes» provocó una fragmentación de las instituciones y la dispersión de las problemáticas relacionadas con la movilidad de las personas entre diversos organismos: OIT, ACNUR, ACNUDH, sin mencionar a la Organización Internacional para las Migraciones (OIM), que no forma parte del sistema de la ONU, pero que se ha expandido considerablemente en las dos últimas décadas (Geiger y Pécoud, 2014).

A principios de los años noventa, los retos migratorios aparecen de nuevo en la escena internacional, esta vez a la luz de una perspectiva más socioeconómica que jurídica, relacionados en particular con la cuestión del desarrollo. El contexto de posguerra fría era doblemente favorable para ello. El fin de la oposición sistemática entre Estados Unidos y la Unión de Repúblicas Soviéticas Socialistas (URSS) permite vislumbrar la posibilidad de crear un consenso mundial en torno a ciertas cuestiones «ajenas a la seguridad» o «sociales» (como la migración o el desarrollo, al igual que los derechos de las mujeres, el medio ambiente, el racismo, etcétera). Además, las 
migraciones comienzan a ser percibidas como una amenaza para la estabilidad de los países: el derrumbe de la URSS, la guerra de los Balcanes, las posibles consecuencias del cambio climático sobre los desplazamientos de personas, las redes mafiosas que "trafican migrantes», son factores que, en un contexto de globalización creciente, inspiran el temor a los gobiernos de que los flujos migratorios se salgan de su control. Y aunque dicho temor provocó esencialmente el refuerzo del control de las fronteras, también facilitó la búsqueda paralela de «soluciones» a los "problemas» planteados por las migraciones, como por ejemplo la cooperación multilateral. Semejantes contextos de crisis son propicios para los or, que pueden «aprovecharlo» para proponer soluciones a los Estados y mostrarse como un respaldo posible (Ambrosetti y Buchet de Neuilly, 2009).

Es por esta razón que la Declaración del Cairo, firmada al culminar la Conferencia Internacional sobre la Población y el Desarrollo en 1994, incluye un capítulo dedicado a las políticas migratorias. Desde los años 2000, asistimos a una multiplicación sin precedentes de iniciativas internacionales relacionadas con el fenómeno de la migración. En particular, podemos mencionar la publicación de informes oficiales (véase más adelante), la organización de conferencias internacionales (como el Diálogo de Alto Nivel sobre la Migración Internacional y el Desarrollo en la onU, organizado en 2006 y en 2013, o el Foro Global sobre Migración y Desarrollo, que tiene lugar cada año desde 2007), y las reconfiguraciones institucionales (como la creación, en 2006, del Grupo Mundial sobre Migración, que reúne los or que trabajan en el campo de la migración).

\section{EL NACIMIENTO DE UN DISCURSO INTERNACIONAL SOBRE LA MIGRACIÓN}

El surgimiento de la migración como un cometido legítimo de los or se vio acompañado de la gestación de lo que podría calificarse como un «discurso internacional sobre la migración» (DIM). Este discurso propone una visión integral de los desafíos migratorios: en él se identifican tanto los problemas como

$38 \frac{\text { SEGUNDO SEMESTRE } 2015}{\text { MIGRACIÓN Y DESARROLLO NÚM. } 25}$ 
las soluciones y, al mismo tiempo, se acredita una manera de encarar dichos desafíos fundada en la cooperación entre los gobiernos y la implicación de los or. Ciertamente, para que un asunto alcance un nivel internacional y pueda ser objeto de debates o de proyectos en los que participen varias naciones, es necesario que antes exista una opinión compartida por todos los actores involucrados, comenzando, en este caso, por los países de origen y de destino. Ante las divergencias de enfoque y de intereses existentes entre estos últimos, el Dim propone una interpretación sosegada y consensual de las cuestiones migratorias, sin la cual éstas no podrían figurar en el orden del día del debate internacional. Si bien el Dim no resuelve los desacuerdos, sí constituye una base común que permite el esbozo de las concertaciones (Pécoud, 2015).

Las remesas y, más ampliamente, las relaciones entre migración y desarrollo, constituyen el núcleo del Dim. Forman parte de una representación optimista de la migración en la que ésta favorece el desarrollo de los países de origen, responde a las necesidades de los países de destino (en términos de mercado laboral o de demografía en particular) y además permite a los migrantes mejorar su nivel de vida. Este objetivo (llamado triple win, «todos ganan») permite federar los intereses de los Estados y otros actores, como el sector privado (que ve reconocida la demanda de mano de obra extranjera y la flexibilidad) y de lo que las instancias internacionales llaman la «sociedad civil», es decir, las ONG o las asociaciones que trabajan en favor de los derechos y el bienestar de los migrantes (Geiger y Pécoud, 2010).

Estas ideas se encuentran desarrolladas en los informes que componen el corpus del presente artículo. Cabe citar particularmente los siete informes que componen la serie World Migration Reports publicados por la OIM a partir de 2000 (véase en particular: OIm, 2010), el informe de la Comisión Mundial sobre las Migraciones Internacionales (CMMi, 2005), el informe del Banco Mundial sobre las remesas (Banco Mundial, 2005), el Informe sobre Desarrollo Humano del PNUD consagrado en 2009 a las cuestiones migratorias (PNUD, 2009), el informe del secretario general de las Naciones Unidas sobre la migración internacional (ONU, 2006), y el informe de la OIT sobre migración y mano de obra (OIT, 2006). Esta lista no es exhaustiva, pero ofrece 
un panorama general de las ideas que encierra el DIM, y tanto más que estos informes son redundantes y llegan a conclusiones casi idénticas. A pesar de las divergencias que existen entre los distintos organismos (por ejemplo, entre la visión económica neoclásica del desarrollo del Banco Mundial y la visión de "desarrollo humano» del PNUD), el análisis del contenido de estos informes revela sobre todo, como se verá más adelante, que existe una convergencia intelectual e ideológica.

Ahora bien, sería completamente legítimo preguntarse por qué leer y, con mayor razón todavía, por qué analizar el Dim. Ciertamente, se trata de un corpus de informes que no sólo son repetitivos, sino a menudo indigestos y de una escritura mediocre, cuya repercusión concreta sobre la realidad y las políticas migratorias es además discutible. He ahí una de las características de los discursos internacionales en su conjunto: la onu y sus distintas agencias han producido a lo largo de décadas una cantidad imponente de informes acerca de una gran variedad de temas, acompañados de «recomendaciones» que permanecen, a menudo, en letra muerta. Asimismo, estos documentos exponen objetivos extraordinariamente ambiciosos (desarrollo, paz, derechos humanos, etcétera) que contrastan a la vez con los limitados recursos de las instituciones que los producen y con su tono tecnocrático, mesurado y apolítico (Rist, 2002). Se podría temer entonces que el DIM descanse dentro de poco en el cementerio de las buenas intenciones y que su capacidad de modificar la situación migratoria sea tan limitada que ni siquiera valga la pena leerlo.

El presente artículo se apoya en un postulado distinto. Efectivamente, con frecuencia se ha observado que, si bien los or no pueden influir directamente en el curso de los acontecimientos, sí pueden proponer lecturas de la realidad que se revelan influyentes (Barnett y Finnemore, 1999). La onU ha desempeñado un papel importante en la promoción de conceptos, valores o normas que estructuran la manera en la que un gran número de protagonistas perciben y evalúan la realidad. Por ejemplo, las nociones de «desarrollo», con sus variantes «sostenible» o "humano», o de "seguridad humana», que aunque no han sido directamente creadas por la onu, bien le deben una gran parte de su popularidad al uso masivo que esta institución ha hecho de ellas. 
Además, la popularidad de estas nociones puede perdurar incluso si se fracasa en el intento de ponerlas en práctica. Por ejemplo, los esfuerzos en términos de "desarrollo» no consiguieron que los países «en vías de desarrollo» dieran alcance a los países «desarrollados» (Nay, 2010); y a pesar de ello la noción misma de desarrollo permanece como uno de los principales criterios con los que se piensa y se organiza actualmente el mundo.

A esta función normativa se suma el papel de los or en la producción de datos. Como se verá enseguida, en el caso de las remesas, el Banco Mundial no solamente ha contribuido al establecimiento de un marco conceptual y político según el cual esas sumas de dinero son vitales para el desarrollo y deben ser reconocidas como tales por los Estados. Igualmente, ha producido los datos, retomados después por muchas otras organizaciones (e investigadores), que sirven de base a este marco analítico. Esta dinámica corresponde a la voluntad de establecer políticas «fundadas en hechos» (evidence-based), lo que confiere cierta influencia a las instituciones que generan los datos.

\section{Remesas, DesarRollo y migRación en el dim}

La relación entre migración y desarrollo representa el núcleo del DIM y refleja sus contradicciones y ambigüedades. Reúne, en efecto, dos preocupaciones parcialmente incompatibles: desde el punto de vista de los países de destino, el reto es el control del flujo migratorio y el desarrollo de las regiones de origen con el fin de reducir el potencial migratorio; para los países de origen, es que la migración sea una fuente de ayuda al desarrollo (Badie et al., 2008). He ahí un ejemplo particularmente claro de cómo el Dim plantea las cuestiones migratorias de tal manera que vuelve posible, al menos en apariencia, crear nexos entre los intereses divergentes de los países. La relación entre migración y desarrollo comprende tres preocupaciones principales: 1) la fuga de cerebros y la pérdida de población calificada que la emigración representa para los países de origen; 2) el papel de la «diáspora», es decir, de las comunidades de migrantes, en el desarrollo de sus regiones de origen, y 3 ) las remesas. 
Estos tres elementos están estrechamente ligados (Freitas, Levatino y Pécoud, 2012). Es difícil negar el problema de la fuga de cerebros que los gobiernos de los países de origen y las ONG exponen regularmente, y que el DIM apenas aborda. Haciendo una explicación esquemática, el problema consiste en que los países de destino tienen interés en atraer inmigrantes calificados y capaces de integrarse sin mayor problema en su mercado laboral; y, por el contrario, los países de origen tienen interés en retener esa población, cuya formación ha sido, en ocasiones, financiada por el Estado y que podría responder a sus necesidades en materia de desarrollo (en sectores como salud, educación, investigación y desarrollo, etcétera). Por lo que resulta bastante delicado alcanzar un entendimiento (Levatino y Pécoud, 2012). Una posible solución depende de la «diáspora del conocimiento», o sea, de los migrantes calificados que pueden regresar a sus países e invertir o participar en proyectos a distancia gracias a las nuevas tecnologías, etcétera (Meyer, 2008). Y aunque esta solución parece sencilla y atrayente, implica un conjunto de condiciones que no siempre se encuentran reunidas, a saber, la voluntad de los migrantes y la posibilidad de viajar de un país a otro, lo que no es siempre compatible con las estrategias de los gobiernos en materia de control de la migración. En este contexto, las remesas son la ilustración más clara de la relación entre migración y desarrollo; contrariamente al papel de la diáspora, al parecer, es fácil contabilizar el monto de estos envíos de fondos y «probar» la influencia positiva de la migración en el desarrollo.

El Banco Mundial realizó un informe exclusivamente consagrado a las remesas titulado Economic Implications of Remittances and Migration (Banco Mundial, 2005). Este documento tiene tres objetivos: 1) comprender la dinámica del envío de remesas y los factores que determinan su volumen y su destino; 2) analizar el efecto (macro y microeconómico) sobre la pobreza, el consumo, la desigualdad, las inversiones, etcétera, y 3) estudiar de qué manera las políticas deberían ocuparse de las remesas para mejorar sus efectos sobre el desarrollo. El enfoque es científico y normativo: no sólo se busca entender qué son las remesas, sino también identificar lo que deberían ser y las estrategias necesarias para alcanzar este objetivo. A través de sus distintos estudios sobre el tema, el Banco Mundial ha llevado el envío y recep- 
ción de remesas al centro del debate sobre migración y desarrollo, y ha hecho que se conviertan en el objeto de políticas públicas, un objeto digno de la atención de los gobiernos y de los expertos en desarrollo.

Según el Dim, las remesas presentan numerosas ventajas. Por un lado, representan sumas muy importantes, y, por otro, su carácter anticíclico las hace menos aleatorias que otras fuentes de ingresos:

Las remesas hoy representan casi el triple del valor de la ayuda oficial al desarrollo proporcionada a los países con bajos ingresos y constituyen, después de la inversión directa extranjera, la segunda fuente de financiamiento externo para los países en desarrollo. Es notable que las remesas por lo general sean más previsibles y estables que las inversiones directas extranjeras y la ayuda oficial al desarrollo.

[...] Según la información acopiada por el Banco Mundial, cuando un país afronta dificultades políticas o económicas, los ciudadanos que viven y trabajan en el exterior ayudan a sus compatriotas enviando más dinero a su país (CMMI, 2005: 28).

Así pues, el efecto de las remesas en las regiones de origen es positivo:

Sin duda, las remesas ofrecen beneficios directos e inmediatos a sus receptores, muchos de los cuales [...] figuran entre los miembros más pobres de la sociedad. Las remesas ayudan a sacar de la pobreza a sus destinatarios, aumentan y diversifican los ingresos de los hogares, aseguran contra riesgos, ofrecen a los miembros de la familia posibilidades de educarse y capacitarse y constituyen una fuente de capital para el establecimiento de pequeñas empresas. Cuando las remesas se usan para comprar bienes y servicios o cuando se invierten en proyectos comunitarios o en empresas que exigen mano de obra, no sólo benefician a los parientes de las personas que trabajan en el exterior (CMMI, 2005: 29).

Sin embargo, el DIM admite «diversos aspectos negativos» de las remesas (CMMI, 2005: 31), particularmente en lo que se refiere a la inequidad de su distribución en los países de origen, la irregularidad de los montos (que tienden a disminuir a medida que los migrantes se instalan de manera durable en el 
extranjero), la presión social y psicológica que pesa sobre los migrantes para que envíen cantidades importantes, y la dependencia, el efecto disuasivo para el trabajo, el consumismo que pueden propiciar en las regiones de origen. Con todo, estos defectos no llevan al DIM a cuestionar su propia insistencia respecto a las remesas, por el contrario, lo llevan a distinguir entre «buenas» $\mathrm{y}$ «malas» remesas y a elaborar estrategias para favorecer las primeras en detrimento de las últimas.

\section{LOS OI Y LA INVESTIGACIÓN CIENTÍFICA}

A esta altura, surge una pregunta que merece la pena plantear, se trata de la compatibilidad de los argumentos del DIM con la investigación científica sobre las remesas. Esta última se ha desarrollado de manera considerable desde hace unos años y ha permitido conocer mejor los mecanismos socioeconómicos que intervienen en el envío y recepción de remesas, así como sus efectos sobre la sociedad y la economía de los países de origen de los migrantes. Como se indicó anteriormente, los or tienden a justificar sus recomendaciones mediante datos empíricos, por lo que resulta lógico interrogarse acerca del grado de convergencia entre los estudios disponibles y las posturas que sostiene el DIM. Si bien esta interrogación es en apariencia simple y consecuente, existen dos razones principales que la vuelven extremadamente compleja.

La primera proviene de la heterogeneidad de los resultados científicos. En las reseñas de los trabajos disponibles se señala con frecuencia que resulta imposible desprender conclusiones que van en un mismo sentido a partir del gran número de estudios sobre las remesas (Ghosh, 2006; De Haas, 2005; Kapur, 2004). En función del país considerado, el periodo, la escala y el método de análisis, los resultados son diferentes. Incluso el estudio de un solo caso empírico puede plantear resultados difíciles de interpretar: por ejemplo, las remesas pueden sacar de la pobreza a algunos segmentos de la población del país de origen de los migrantes y, al mismo tiempo, generar una situación de dependencia poco propicia para el desarrollo. Encima, los estudios se 
encuentran divididos según distintos enfoques: especialmente, la distancia que separa los estudios económicos y los de orientación socioantropológica vuelve muy difícil una interpretación global de los resultados. A pesar de todo, esta situación no es sorprendente; lo asombroso sería que la mayoría de los estudios convergiera hacia un mismo resultado. Frente a tal indeterminación, los or generalmente hacen resaltar la necesidad de obtener mejores datos y de realizar más investigaciones. No obstante, Carling pone en duda, y con razón, que exista incluso la posibilidad de desprender alguna «verdad» sobre las remesas (2008: 59). A este respecto, el DIM se apoya en la ilusión, frecuente pero desacertada, de que los hechos hablarán por sí mismos y que basta con estudiar la realidad para comprenderla y mejorarla.

La segunda razón está menos relacionada con el contenido de los trabajos disponibles y más con las condiciones en las que éstos son llevados a cabo. La cuestión de la validación de las tesis del Dim a través de los trabajos de investigación sobre las remesas tiene sentido únicamente si podemos suponer cierta independencia entre la generación de conocimiento y el debate político. Carling (2008: 45) subraya el crecimiento espectacular del número de estudios sobre las remesas desde hace unos 20 años, hecho que no se explica tanto por el aumento de las sumas de dinero en cuestión (el volumen de las remesas ha aumentado en una proporción bastante menor que los estudios sobre el tema), sino, más bien, por el interés de la política en sus consecuencias sobre el desarrollo. Esta relación entre el interés político y científico se manifiesta en las problemáticas que se elige tratar. Al revisar las publicaciones existentes, se constata que la mayoría de los estudios sobre las remesas se plantean sin cesar más o menos la misma pregunta relacionada con los efectos de éstas sobre el desarrollo, retomando así las preocupaciones del DIM. Aun cuando dichos estudios no validan las posturas políticas del DIM, se inscriben en un marco paradigmático modelado en gran parte por el interés político por las remesas. Y como es difícil disociar el debate normativo de las discusiones científicas, el Dim argumenta apoyándose en estudios que él mismo ha contribuido a suscitar. De manera más inmediata, dichos vínculos entre la generación de conocimiento y el debate político se verifican en los informes que conforman el corpus de este artículo, escritos, 
efectivamente, en colaboración con los principales especialistas de las cuestiones migratorias. He aquí uno de los efectos de la influencia cognitiva de los or evocada líneas más arriba: al ampararse de un tema, éstas contribuyen a definir una agenda política y científica que ejerce cierta influencia sobre otros actores (por ejemplo, los investigadores, pero también las ONG).

\section{El Estado, LOS BANCOS Y LOS MIGRANTES}

El DIM no se limita a analizar los mecanismos en juego en el envío y recepción de remesas o sus consecuencias en los países de origen de los migrantes; también aspira a emplear estos conocimientos para elaborar recomendaciones políticas dirigidas a los Estados. Este enfoque normativo plantea inmediatamente la cuestión de la legitimidad de la intervención del Estado en lo que concierne a la gestión de los recursos privados de los migrantes. El DIM se interesa en este problema y no cesa de proclamar su respeto del carácter privado de estas sumas de dinero. "Fundamentally, remittances are private funds»: afirma el Banco Mundial (2005: xvi). Según la CMmi (2005: 29), «Primero, es esencial reconocer que los giros son un recurso privado que pertenece a los migrantes y a sus familias».

Sin embargo, en paralelo, estos mismos informes dedican cientos de páginas a la reflexión sobre cómo aprovechar mejor ese dinero. De esta manera, la CMMI prosigue y señala que: «El volumen de las remesas recibidas por muchos países de origen hoy es tan elevado [...] que es esencial encauzar su potencial hacia la promoción del crecimiento económico a largo plazo» (2005: 30). De ahí, una oscilación permanente del Dim entre la voluntad de intervenir y el respeto a la autonomía de los migrantes. De acuerdo con la ONU: "Queda mucho por hacer para aumentar los beneficios de las remesas respetando al mismo tiempo su carácter de fondos privados» (2006: 14).

Para superar esta contradicción, el DIM pretende instruir a los migrantes para que éstos tomen por sí mismos la decisión «correcta» con respecto a las remesas. Según la oIT (2006: 33), se necesita «proporcionar incentivos para promover la inversión productiva de las remesas en los países de origen». La 
CMMI sugiere que «los migrantes y los beneficiarios de las remesas deben contar con la capacidad para tomar decisiones fundamentadas sobre el uso de estos recursos. Es necesario ayudar a los hogares y comunidades de los países de origen a utilizar de modo eficaz las remesas recibidas, gracias a un aprendizaje adecuado y al acceso a dispositivos de microcrédito» (2005: 30). No se precisa de qué tipo de «formación» se trata, pero esta recomendación muestra el carácter normativo del Dim. Por supuesto que los migrantes son libres de disponer de sus ingresos a su antojo, pero de igual modo sería conveniente que decidieran «libremente» gastarlos de una manera que favorezca al desarrollo. Bakewell (2008) apunta el carácter moralizador de este tipo de argumento, que implica que los migrantes tienen una responsabilidad particular ante su país de origen y que aquellos que gastan de manera «inútil»su dinero (consumiendo en lugar de invertir, por ejemplo) cometen una falta moral (un reproche que raramente se hace a los ciudadanos de los países desarrollados).

En el mismo orden de ideas, el DIM interfiere en la economía de las familias de los migrantes transnacionales al manifestar su preferencia por ciertos mecanismos para la toma de decisiones. Y lo mismo sucede con el papel de la mujer: el PNUD (2009: 82) elogia la tendencia de éstas a «enviar mayor proporción de sus ingresos a casa y de manera más regular, aunque los montos totales suelen ser menores debido a que sus salarios son más bajos» que los de los hombres; con todo, se considera la migración de las mujeres como benéfica. Igualmente, se estima que las mujeres emplean mejor el dinero que reciben: según la CMMI, "las mujeres usan las remesas con más eficacia» (2005: 30) y por ello es conveniente hacer que crezca su influencia en la gestión de los recursos de las familias de los migrantes.

Otra de las preocupaciones concierne a la relación entre los migrantes y sus familiares que permanecen en su país, y a quienes se considera menos dignos de confianza. El DIM opina que si bien los migrantes trabajan duro para ayudar a sus familias, el dinero que envían es a menudo mal utilizado, debido especialmente a la distancia que los separa de sus familias y los hace incapaces de influir en cómo se emplea ese dinero. En consecuencia, se tendría que "permitir que los migrantes ejerzan un mayor control sobre el uso 
del dinero que envían, ofreciéndoles la oportunidad de comprar bienes o servicios directamente, en lugar de dejar estas transacciones en manos de los miembros del hogar» (CMMI, 2005: 30). De ahí también el llamado a alentar una gestión colectiva de las remesas en manos de los mismos trabajadores migrantes. El caso de las organizaciones de migrantes (Hometown Associations) es frecuentemente citado como un modelo. Estas asociaciones, que aparecieron en los años noventa y reúnen migrantes latinoamericanos residentes en Canadá y Estados Unidos, permiten centralizar los fondos e invertirlos en proyectos colectivos en beneficio de las regiones de origen. Como señala la CMMI: "Las asociaciones de ciudadanos oriundos de la misma ciudad y las asociaciones de diásporas pueden ayudar a recaudar y transferir remesas colectivas a su localidad de origen, remesas que pueden utilizarse para proyectos de infraestructura y de otra índole, aportando beneficios a comunidades enteras y no sólo a algunos hogares» (CMMI, 2005: 30; véase igualmente Banco Mundial, 2005: 95-96).

Otra estrategia para aumentar la repercusión de las remesas consiste, según el Dim, en evitar que este dinero sea transferido por el circuito informal recurriendo a los servicios de bancos e instituciones financieras. Según la OIM: "It is generally agreed that remittances transferred through formal rather than informal systems are more likely to be leveraged for development» (2010: 47-48). Además: «Las transferencias de dinero oficiales y registradas son preferibles a los flujos no oficiales porque reducen el riesgo de que los migrantes y los destinatarios sean explotados por redes clandestinas de lavado de dinero» (CMmi, 2005: 30). De acuerdo con la oim, los medios para alcanzar este objetivo son claros:

The best ways to optimize formal remittance flows are already well understood. These include reducing the costs and increasing the speed and efficiency of formal transfers - for example, through the promotion of competition between transfer providers; disseminating information to both migrants and receivers about opportunities for formal transfers and the risks of informal transfers; providing training in financial literacy; and promoting the development of new technologies for money transfer (for instance, using cell phones) (OIM, 2010: 48). 
El DIM critica de manera unánime los servicios de las instituciones financieras que, como Western Union, imponen precios «escandalosos» (CMmI, 2005: 29) que desalientan a los migrantes y los incitan a utilizar los circuitos informales. Así pues, la CMmi recomienda «fomentar una mayor competitividad en el sistema oficial de transferencias», lo que permitiría «una mayor transparencia en el sector de los servicios financieros para que los migrantes puedan comparar fácilmente las tarifas de envío de dinero de los diversos proveedores de servicios» (2005: 29). Asimismo, la ort habla de «reducir los costos de las transferencias de remesas, inclusive mediante la facilitación de unos servicios financieros accesibles, la reducción de las comisiones por transacciones, el suministro de incentivos fiscales y la promoción de una mayor competencia entre las instituciones financieras» (2006: 33-34). De esta manera, los migrantes se convertirían en clientes entendidos y bien informados sobre los servicios bancarios con buenas prestaciones, gracias a "programas de formación financiera para ayudar a los migrantes a comprender mejor y a acceder a los sistemas bancarios oficiales de los países de destino» (CMMI, 2005: 30). ${ }^{2}$

El papel de los Estados es entonces trabajar en el establecimiento de un sistema bancario más favorable para los migrantes y los envíos de remesas: "Los gobiernos pueden adoptar muchas medidas para aumentar la competencia en el mercado de remesas y mantener la presión en favor de una reducción de las comisiones [...] También es importante ampliar el acceso a bancos y servicios bancarios» (ONU, 2006: 72). En términos más generales, los Estados deben esforzarse por actuar «a la altura» de las remesas. El DIM considera que éstas pueden tener un efecto positivo en el desarrollo solamente si los países de origen ofrecen un contexto favorable: «La recepción de remesas a gran escala y a largo plazo tendrá pocas probabilidades de contribuir al

${ }^{2}$ La necesidad de «instruir» a los migrantes es señalada de manera recurrente por el DIM. De una manera un tanto paternalista, este último considera en efecto que los migrantes están a menudo mal informados, son ingenuos o ignorantes, lo que los conduce a tomar malas decisiones. Así, la inmigración ilegal podría ser explicada en parte por las ilusiones que los migrantes potenciales se hacen acerca de la vida en los países de destino; por lo que realizar campañas de información (o de «sensibilización») podría permitir disipar ilusiones y modificar los comportamientos (Pécoud, 2010). 
crecimiento sostenible si no existen sistemas financieros sólidos, divisas estables, un clima favorable para las inversiones y una administración honrada» (CMmi, 2005: 31). El Banco Mundial (2005: xi) advierte que la contribución de los migrantes al desarrollo no dispensa a los países menos desarrollados de la tarea de establecer políticas adaptadas para su fomento: «However, migration should not be viewed as a substitute for economic development in the origin country - development ultimately depends on sound domestic economic policies». Dicho de otra manera, las remesas, lejos de relegar a los Estados a un papel pasivo, por el contrario, reactivan los principios de "gobernanza» firmemente establecidos en los países menos desarrollados.

\section{ZONAS GRISES DE UN MUNDO IDEAL}

En el mundo imaginado por el DIM, los migrantes se preocupan por el desarrollo de sus comunidades de origen y deciden juiciosamente la mejor manera de utilizar el dinero que envían con ese destino. Para ello, cuentan con la ayuda de un sistema bancario en el que reina una sana competencia, que permite a migrantes bien informados acceder a servicios financieros de buena calidad con las mejores tarifas. Los distintos gobiernos se encargan de favorecer dicha competencia entre instituciones bancarias al tiempo que crean un ambiente económico favorable para las inversiones de los migrantes. De esta forma, el Dim perfila un horizonte ideal, el cual deberían procurar alcanzar tanto los gobiernos, como el sector privado y los propios migrantes.

El DIM no presenta ese mundo ideal como una opción entre otras tantas sino un escenario deseable en todos sus aspectos, en el que todos salen ganando y que, por consiguiente, nadie podría objetar. El hincapié que se hace sobre los «datos» sugiere que el mundo imaginado por el Dim no es fruto de una ideología o de una reflexión política, sino el resultado de un razonamiento objetivo sobre la mejor manera de optimizar la situación mundial. Este tipo de reflexión no es nuevo: ese enfoque apolítico y tecnocrático es una de las formas contemporáneas del poder (Shore y Wright, 1997), que se observa de manera particularmente clara en la retórica y las prácticas de 
los oI (Müller, 2009). Debido a su carácter intergubernamental, estas últimas no pueden pretender desempeñar un papel político o adoptar una postura abiertamente ideológica — de ahí la insistencia sobre el «análisis experto» y la función «técnica» a la que dicen aspirar-. Por ello es preciso analizar lo que se encuentra bajo la superficie y revelar, al menos en parte, lo que se esconde detrás de esa revalorización de las remesas.

La primera observación que podemos hacer tiene que ver con los intereses de los propios or y el contexto en el que se elabora el Dim. El intento por incluir el tema de las remesas en los debates sobre el desarrollo se lleva a cabo en un contexto desfavorable: la opinión dominante en el ámbito del desarrollo se muestra aún bastante indiferente ante los desafíos migratorios, que se encuentran ausentes de los Objetivos de Desarrollo del Milenio (ODM) fijados en 2000 para ser alcanzados en 2015. Uno de los objetivos del Dim es subsanar esta carencia y que la migración se vuelva uno de los elementos de las políticas de desarrollo. Así, por ejemplo, el PNuD constata que: «A la fecha, las estrategias nacionales de desarrollo y reducción de la pobreza en los países en desarrollo no reconocen el potencial de la movilidad [... ]» (2009: 91). En la medida en que la época actual se encuentra marcada por los debates acerca de lo que sucederá «después de 2015» (es decir, acerca de la doxa sobre el desarrollo que se impondrá tras la expiración de los ODM), cada OI hace despliegue de su calidad de experta y ambiciona establecerse como protagonista en el marco de las políticas por venir. De tal forma que el DIM es abiertamente pro domo: el PNUD afirma, por ejemplo, que: «La asesoría que prestan los organismos especializados puede ser muy provechosa para los gobiernos» (2009: 124) —organismos entre los que se encuentra naturalmente el PNUD- Dinámica alentada por el contexto de rivalidad existente entre los oI.

Skeldon (2008) apunta además que el hecho de asociar la migración y el desarrollo es una estrategia creada en respuesta a las reticencias de los Estados ante la intervención de instancias internacionales en el ámbito de la migración. Establecer sistemáticamente un vínculo entre un tema políticamente delicado como la migración y un asunto consensual e incuestionado como el desarrollo permite legitimar la utilidad de los or en la problemática de las migraciones internacionales. En semejante contexto, las remesas 
representan la mejor "prueba», observable y cuantificable, de la incidencia de la migración sobre el desarrollo; y constituyen un argumento de peso para convencer a los Estados de tomar en cuenta las circunstancias migratorias en las políticas de desarrollo, y para confiar a los or la tarea de llevar a cabo proyectos que asocien migración y desarrollo.

Dicho vínculo es entonces el producto de una construcción de la realidad -construcción que no es tan natural ni tan evidente como el Dim querría hacerlo creer, y no tan necesariamente consensual y neutral desde una perspectiva política o ideológica (Geiger y Pécoud, 2013)—. Detrás del Dim, o al margen de éste, existe un conjunto de elementos que no son retenidos para su construcción de la realidad. Es el caso, por ejemplo, de las interacciones entre políticas comerciales y migración; según algunos estudios, las subvenciones de los países desarrollados a su sector agrícola perjudican a los países menos desarrollados, ya que les impiden exportar sus productos a un precio competitivo; hecho que reduce las perspectivas de empleo de estos países y propicia la emigración (Martin y Abella, 2009). Y si bien, este tema es abordado por la CMmi (2005: 14), nunca es realmente desarrollado. Otro ejemplo es el comercio de armas y sus consecuencias sobre la estabilidad en ciertas regiones de fuerte emigración; asunto probablemente demasiado delicado para que sea abordado por el DIM. En otras palabras, la asociación «migración y desarrollo» no es forzosamente infundada, pero oculta otro tipo de asociaciones («migración y políticas comerciales», «migración y venta de armas»), que no son planteadas nunca y no aparecen en la agenda de los oI, ni, de manera más general, en los debates académicos y políticos sobre la migración.

Otros observadores han señalado que el interés de los or y de los agentes del desarrollo por las remesas se debe a la ideología que domina actualmente este debate. Después del discurso fundador de Truman en 1949, el desarrollo ha sido el objeto de distintas doctrinas sucesivas. Como observa Rist (1996), el fracaso de un paradigma lleva a la creación de uno nuevo, que se supone es el remedio de las insuficiencias anteriores. En este ámbito, se observa que el mundo de las remesas rehúye los macroproyectos dirigidos por los gobiernos o por las grandes empresas, y prefiere la microiniciativa individual. En consecuencia, se estima que los migrantes y los ciudadanos de los países 
menos desarrollados pueden convertirse en empresarios y pueden mejorar su situación gracias a los recursos comunitarios, sin esperar la ayuda de su gobierno. Según esta visión empresarial, e incluso neoliberal, el Estado y su burocracia ceden su lugar a los individuos y las instituciones financieras, y eso podría ayudar a evitar los problemas de corrupción, clientelismo y otras formas de utilización inadecuada de fondos que podrían destinarse al desarrollo (Kapur, 2004; Simmons, 2008).

Se puede deducir que las esperanzas puestas en las remesas corresponden tal vez tanto a una "moda» ideológica y política como a una realidad empíricamente observable. Como se apuntó anteriormente, de los datos y los estudios disponibles se desprenden resultados contrastados. De acuerdo con Muhirwa (2012), las remesas tienen un efecto limitado sobre el desarrollo y, sobre todo, no compensan las pérdidas ocasionadas por la emigración de personas calificadas. Su actual popularidad no es causada únicamente por "los hechos», también se debe a que las remesas son compatibles con los intereses políticos de los Estados y, en particular, de los Estados de destino. En este sentido, podemos señalar la relación entre las remesas y los programas de migración laboral temporal. Estos programas son el objeto de un nuevo interés (Castles, 2006) y de numerosas recomendaciones del DiM: «Los Estados y el sector privado deben considerar la opción de introducir programas de migraciones temporales cuidadosamente diseñados como medios para colmar las necesidades económicas de los países de origen y de destino» (CMmi, 2005: 18).

Este tipo de programas permiten que los países de destino contraten los migrantes que estimen necesarios, y que los países de origen obtengan una garantía de su regreso (lo que ayuda en particular a evitar la fuga de cerebros). Incluso si esto se menciona raramente de manera explícita, estos programas facilitan la prevención de los «problemas» ligados a la integración social y evitan los gastos ocasionados por la presencia de la familia del trabajador migrante, ya que éste (o ésta) emigra solo(a). ${ }^{3}$ Desde la óptica del

${ }^{3}$ Este argumento aparece en la encuesta de la onu titulada World Economic and Social Survey 2004, que apunta que: "For destination countries, temporary migration might present fewer difficulties of social integration» (ONU, 2004: xx]. Notemos que esta valorización de 
envío y recepción de remesas, la migración temporal representa una opción atractiva: los migrantes no se instalan de manera durable y su familia permanece en su país, dos condiciones que se sabe aumentan las sumas de dinero enviadas. A menudo se cita a las Filipinas como un ejemplo de este modelo «exportador» de millones de ciudadanos desde hace varias décadas, es uno de los países que mayor cantidad de dinero recibe de sus emigrantes (véase cmmi, 2005: 19).

La revalorización de las remesas es entonces plenamente compatible con los intereses de los Estados y puede contribuir a justificar una forma de statu quo de las políticas migratorias, puesto que los programas de migración laboral temporal han sido ampliamente aplicados en Europa (especialmente durante los años treinta, edad de oro del capitalismo) y son actualmente una forma de migración laboral dominante (por ejemplo, en los países del Golfo Pérsico).

\section{CONCLUSIÓN}

En algunas publicaciones recientes (véase en particular Ketkar y Ratha [2009]), el Banco Mundial expone algunas ideas sobre cómo podrían utilizarse las remesas para facilitar la inserción de los países pobres en el mecanismo de las finanzas internacionales. Se estima que dicha inserción se ha vuelto necesaria a causa de la disminución de los fondos públicos dedicados al desarrollo que obliga a los países menos desarrollados a recurrir a distintos modos de financiamiento privados (llamados «innovadores»). Una de las ideas exploradas consiste en utilizar las remesas como una garantía de recursos a mediano y largo plazo. Sabemos que la dificultad de los Estados pobres que buscan financiamiento en los mercados internacionales proviene de su escasa credibilidad, factor que aumenta el riesgo (y en consecuencia, el

la migración laboral temporal es difícilmente compatible con otros objetivos reivindicados por el DIM, como el acceso a ciertos derechos (la no discriminación o la reagrupación familiar, por ejemplo) o lo que los or llaman la «cohesión social». De ahí, se desprende un conjunto de contradicciones internas del DIM, que minan su coherencia.

$54 \frac{\text { SEGUNDO SEMESTRE } 2015}{\text { MIGRACIÓN Y DESARROLLO NÚM. } 25}$ 
costo) de sus préstamos. En este contexto, la existencia de ingresos considerados como estables, como es el caso de reservas de materias primas (principalmente gas y petróleo), es una gran ventaja, ya que los bancos pueden exigir que esos ingresos sean empleados prioritariamente para el reembolso de los créditos que conceden. Para los países que no cuentan con semejantes recursos pero tienen una gran población de emigrantes, las remesas podrían facilitar el acceso al crédito, en la medida en que éstas son juzgadas como estables, contracíclicas y poco predispuestas a declinar en el futuro.

Si bien - en mi conocimiento-, estas reflexiones no han sido el objeto de recomendaciones formales en informes como los que componen el DIM, éstas constituyen la prolongación lógica de su visión de las remesas. Como hemos visto, el DIM se preocupa por incluir las remesas en los circuitos financieros legales y por evitar la circulación informal y no declarada de moneda. Otro de sus objetivos es, por un lado, transformar los migrantes en clientes bien informados de las instituciones financieras, ofreciéndoles formación y, por otro lado, reducir las comisiones cobradas por los bancos, fomentando mayor competencia entre las instituciones. Ciertamente, sólo bajo estas condiciones las remesas podrán ser el objeto de los planes de financiamiento previstos por el Banco Mundial. La introducción de las remesas en los planes de financiamiento del desarrollo exige un conocimiento profundo del volumen y la naturaleza de estos flujos de dinero porque, sin ir más lejos, es indispensable para avanzar previsiones. He aquí una ocasión de apreciar una vez más el trabajo, a la vez cognitivo y empírico, realizado por los or, y en particular por el Banco Mundial: las remesas no representan ninguna novedad, pero poniéndolas bajo la luz de los proyectores, otorgándoles una función en las políticas de desarrollo, y reuniendo los datos que permiten justificar su importancia, los or transforman completamente su índole. Y las remesas pasan de ser un viejo fenómeno ampliamente ignorado y percibido como marginal, a ser el objeto de políticas públicas y un factor del desarrollo.

Por supuesto, desde un punto de vista estrictamente empírico y realista, nada nos dice que el DIM vaya a lograr modificar la situación actual de las remesas, la realidad no va a cambiar simplemente porque el Banco Mundial 
se interesa en ellas. En este sentido, el DIM no es un discurso "realizativo». ${ }^{4}$ Sin embargo, no hay que olvidar la influencia que ciertos or pueden tener en las políticas de los países menos desarrollados; existe la posibilidad de que algunos gobiernos decidan establecer medidas para orientar el envío de remesas siguiendo la dirección expuesta en el presente artículo. ${ }^{5}$ Y aun si esta representación de las remesas no se ve concretizada en la realidad, sí repercute en la manera en que muchos actores (no sólo los gobiernos, sino también los investigadores, el sector privado y las ong que actúan en el ámbito del desarrollo) conciben los desafíos migratorios. Por esta razón, resulta pertinente explorar atentamente la lógica interna de esta visión del mundo e intentar revelar sus lagunas.

\section{Bibliografía}

Ambrosetti, David e Yves Buchet de Neuilly (2009) «Les organisations internationales au cœur des crises. Configurations empiriques et jeux d'acteur», Cultures et conflits, núm. 75, pp. 7-14.

BADIE, Bertrand, Rony Brauman, E. Emmanuel Decaux, Devin Guilaume y C. Catheribe Wihtol de Wenden (2008), Pour un autre regard sur les migrations, París, La Découverte, 126 pp.

BakeWell, Oliver (2008), «Keeping Them in Their Place: the Ambivalent Relationship Between Development and Migration in Africa», Third World Quarterly, vol. 29, núm. 7, pp. 1341-1358.

Banco Mundial (2005), Global Economic Prospects 2006: Economic Implications of Remittances and Migration, Washington, Banco Mundial, 157 pp.

(2015), Migration and Remittance Flows: Recent Trends and Outlook, Washington, Banco Mundial, Migration and Development Brief, vol. 24, 27 pp.

${ }^{4}$ N. del T.: Lingüística. Un discurso que "hace» o "transforma», no sólo constata.

5 Véase el ejemplo de un proyecto en marcha en el portal de la iniciativa Knomad (http:// www.knomad.org/, consultado el 3 de junio de 2014), en la que el Banco Mundial juega un papel preponderante y que aspira, entre otras cosas, a proporcionar una «asistencia técnica» a los Estados que deseen establecer nuevas políticas en las que se asocie migración y desarrollo.

$56 \frac{\text { SEGUNDO SEMESTRE } 2015}{\text { MIGRACIÓN Y DESARROLLO NÚM. } 25}$ 
Barnett, Michael y M. Finnemore (1999), "The Politics, Power, and Pathologies of International Organizations», International Organization, vol. 53, núm. 4, pp. 699-732.

CARLING, Jorgen (2008), «Interrogating Remittances: Core Questions for Deeper Insight and Better Policies», en S. Castles y R. Delgado Wise (dir.), Migration and Development. Perspectives from the South, Ginebra, oIm, pp. 43-64.

CASTLES, Stephen (2006), "Guestworkers in Europe: A Resurrection?», International Migration Review, vol. 40, núm. 4, pp. 741-766.

Comision Mundial sobre las Migraciones Internacionales (CMMI) (2005), Les migrations dans un monde interconnecté: nouvelles perspectives d'action, Ginebra, CMmI, $97 \mathrm{pp}$.

De Guchteneir, Paul y Antoine Pécoud (2010), "Les obstacles à la ratification de la Convention des Nations Unies sur la protection des droits des travailleurs migrants», Droit et Société, núm. 75, pp. 431-451.

De HAAS, Hein (2005), «International Migration, Remittances and Development: Myths and Facts», Third World Quarterly, vol. 26, núm. 8, pp. 1269-1284.

Fondo Monetario Internacional (FMI) (2009), International Transactions in Remittances. Guide for Compilers and Users, Washington, FMI, 109 pp.

Freitas, Any, Antonina Levatino y A. Antoine Pécoud (2012), «Introduction: New Perspectives on Skilled Migration», Diversities, vol. 14, núm. 1, pp. 1-17.

Geiger, Martin y Antoine Pécoud (dir.) (2010), The Politics of International Migration Management, Basingstoke, Palgrave, 320 pp.

(2013), «Migration, Development and the «Migration and Development Nexus"», Population, Space and Place, vol. 19, núm. 4, pp. 369-374.

(2014), «International Organisations and the Politics of Migration», en M. Geiger y A. Pécoud, Special Issue, «International Organisations and the Politics of Migration», Journal of Ethnic and Migration Studies, vol. 40, núm. 6, pp. 865-887.

Grosh, Bimal (2006), Migrants' Remittances and Development. Myths, Rhetoric and Realities, Ginebra, oIm, 122 pp.

Kapur, Devesh (2004), «Remittances: The New Development Mantra?», G-24 Discussion Paper Series, núm. 29, Nueva York/Ginebra, unctad, 22 pp.

KetKar, Suhas y Ratha Dilip (2009), «Future-Flow Securitization for Development Finance», en S. Ketkar y R. Dilip (dir.), Innovative Financing for Development, Washington, Banco Mundial, pp. 25-57. 
Levatino, Antonina y Antoine Pécoud (2012), "Overcoming the Ethical Dilemmas of Skilled Migration? An Analysis of International Narratives on the "Brain Drain"”, American Behavioral Scientist, 56 (9), pp. 1258-1276.

LevitT, Peggy y Deepak Lamba-Nieves (2011), «Social Remittances Revisited», Journal of Ethnic and Migration Studies, vol. 37, núm. 1, pp. 1-22.

Martin, Philip y Manolo Abella (2009), «Migration and Development: The Elusive Link at the GFMD», International Migration Review, vol. 43, núm 2, pp. 431-439.

Meyer, Jean Baptiste (2008), "La circulation des compétences: un enjeu pour le développement», Annuaire suisse de politique de développement, vol. 27, núm. 2, pp. 53-69.

Munirwa, Jean Marie (2012), «Funnelling Talents Back to the Source: Can Distance Education Help to Mitigate the Fallouts of Brain Drain in Sub-Saharan Africa?», Diversities, vol. 14, núm. 1, pp. 45-62.

Müllek, Birgit (2009), "Comment rendre technique un débat politique. Controverses autour des biotechnologies agricoles au sein de la FAO», Tsantsa, Revue de la Société Suisse d'Ethnologie, núm. 14, pp. 27-36.

Naciones Unidas (2004), World Economic and Social Survey 2004. International Migration, Nueva York, onu, Department of Economic and Social Affai, 188 pp.

(2006), "Migrations internationales et développement», Informe del secretario general, núm. A/60/871, Sexagésimo periodo de sesiones de la Asamblea General de la onu, Nueva York, onv, 99 pp.

NAY, Olivier (2010), "Les politiques de développement», en O. Borraz y V. Guiraudon (dir.), Les Politiques Publiques: changer la société, París, Presses de Sciences Po, pp. 139-170.

Organización Internacional del Trabajo (OIT) (2006), Cadre multilatéral de l'OIT pour les migrations de main-d'euvre, Ginebra, OIT, 97 pp.

Organizacion Internacional para las Migraciones (OIM) (2010), World Migration Report 2010: The Future of Migration -Building Capacities for Change, Ginebra, oIm, $272 \mathrm{pp}$.

PÉCoud, Antoine (2010), «Informing Migrants to Manage Migration? An Analysis of Iom's Information Campaigns», en M. Geiger y A. Pécoud (dir.), The Politics of International Migration Management, Basingstoke, Palgrave, pp. 184-201.

(2015), Depoliticising Migration. Global Governance and International Migration Narratives, Basingstoke, Palgrave.

$58 \frac{\text { SEGUNDO SEMESTRE } 2015}{\text { MIGRACIÓN Y DESARROLLO NÚM. } 25}$ 
Programa de las Naciones Unidas para el Desarrollo (PNUD) (2009), Lever les barrières. Mobilité et développement humains, Nueva York, PNUd, 237 pp.

Rist, Gilbert (1996), Le Développement. Histoire d'une croyance occidentale, París, Presses de Sciences Po, 442 pp.

(dir.) (2002), Les Mots du pouvoir. Sens et non-sens de la rhétorique internationale, París-Ginebra, PUf-IUEd, 208 pp.

Rosental, Paul Andre (2006), "Géopolitique et État-providence. Le BIT et la politique mondiale des migrations dans l'entre-deux-guerres", Annales. Histoire sciences sociales, vol. 61, núm. 1, pp. 99-134.

Shore, Chris y Susan Wright (dir.) (1997), Anthropology of Policy. Critical Perspectives on Governance and Power, Londres, Routledge, 294 pp.

Simmons, Alan (2008), «Why International Banks Became Interested in Migrant Remittances. A Critical Reflection on Globalization, Ideology and International Migration», en C. Gabriel y H. Pellerin (eds.), Governing International Labour Migration, Current Issues, Challenges and Dilemmas, Londres, Routledge, pp. 60-77.

SkeLDon, Ronald (2008), "International Migration as a Tool in Development Policy: A Passing Phase?», Population and Development Review, vol. 34, núm. 1, pp. 1-18. 
